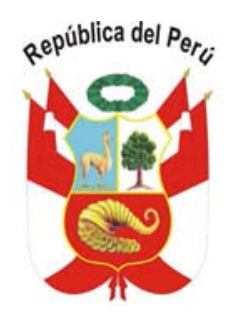

\title{
I Encuentro de Presidentes de Cortes Superiores de Justicia de la República del año 2011
}

\section{DECLARACIÓN}

Los Presidentes de las treinta Cortes Superiores de Justicia del país, firmantes, saludamos la iniciativa de convocar y organizar este Primer Encuentro de Presidentes del año 2011, el que nos ha permitido intercambiar experiencias y propuestas en el marco del Plan de Gobierno Institucional 2011- 2012. En ese sentido, acordamos por unanimidad lo siguiente:

PRIMERO.- Felicitar muy especialmente al señor Presidente del Poder Judicial, Doctor César San Martín Castro, y a los integrantes del Consejo Ejecutivo del Poder Judicial, por su interés y disposición a promover la participación de las Cortes Superiores de Justicia en la elaboración de los planes y estrategias de gestión institucional.

SEGUNDO.- Reafirmar nuestro compromiso de fortalecer las políticas instauradas por el Presidente del Poder Judicial en sus cuatro ejes prioritarios: posicionamiento institucional, modernización de la gestión judicial, acceso a la justicia y lucha contra la corrupción.

TERCERO.- Saludar y respaldar la iniciativa de profesionalizar y descentralizar la gestión administrativa de nuestra institución, apuntalando la co- operación interinstitucional y la constitución progresiva de unidades ejecutoras en los distritos judiciales que correspondan.

CUARTO.- Ratificar la aplicación intensiva de procedimientos modernos de gestión judicial de acuerdo con los estándares del servicio de justicia 
internacional, con especial incidencia en la mejora y optimización de la infraestructura y el uso de nuevas tecnologías en aras de la celeridad, eficiencia y transparencia judicial.

QUINTO.- Incentivar la producción jurisdiccional tendiente a atender la exigencia ciudadana de prestación de un servicio de justicia con calidad; así como asumir decisivamente las estrategias establecidas por los órganos de gobierno, dirigidas a disminuir la carga procesal.

SEXTO.- Comprometer nuestros esfuerzos en la promoción de la justicia de paz, y la mejor articulación del Poder Judicial con la justicia indígena y las fórmulas alternativas de composición de conflictos.

SÉTIMO.- Respaldar las gestiones del Presidente del Poder Judicial ante las instituciones del Estado, para el otorgamiento de beneficios e incentivos económicos a favor de los trabajadores.

Lima, 11 de Marzo de 2011 